Griechisch-römische Komödie und Tragödie 


\title{
DRAMA
}

Beiträge zum antiken Drama und seiner Rezeption

\author{
Herausgegeben von \\ F. De Martino - J. A. López Férez - \\ G. Mastromarco - B. Seidensticker - \\ N. W. Slater - A. H. Sommerstein - R. Stillers - \\ P. Thiercy - B. Zimmermann
}




\section{Band 3}

\section{Griechisch-römische Komödie und Tragödie}

Hrsg. von Bernhard Zimmermann

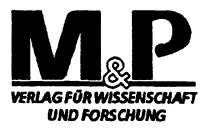


Die Deutsche Bibliothek - CIP-Einheitsaufnahme

\title{
Griechisch-römische Komödie und Tragödie / hrsg. von Bernhard Zimmermann.
}

- Stuttgart: M und P, Verl. fur Wiss. und Forschung, 1995

NE: Zimmermann, Bernhard [Hrsg.]

(Drama; Bd.35)"

ISBN 978-3-476-45059-3

NE: GT

\author{
ISBN 978-3-476-45059-3 \\ ISBN 978-3-476-04216-3 (eBook) \\ DOI 10.1007/978-3-476-04216-3
}

Dieses Werk ist einschließlich aller seiner Teile geschützt. Jede Verwertung außerhalb der engen Grenzen des Urheberrrechtsgesetzes ist ohne Zustimmung des Verlages unzulässig und strafbar. Das gilt insbesondere für die Vervielfältigungen, Übersetzung, Mikroverfilmungen und Einspeicherung in elektronischen Systemen.

M \& P Verlag Für Wissenschaft und Forschung ein Verlag der J.B. Metzlersche Verlagsbuchandlung und Carl Ernst Poeschel Verlag GmbH in Stuttgart

(C) 1995 Springer-Verlag GmbH Deutschland

Ursprünglich erschienen bei J.B. Metzlersche Verlagsbuchhandlung und Carl Ernst Poeschel Verlag GmbH in Stuttgart 1995 


\section{Inhaltsverzeichnis}

\section{P. Reinders}

Der Demos in den Rittern des Aristophanes

am Beispiel des Amoibaions in den Vv. 1111-1150

S. Beta

Aristofane tra sagezza e castità

M. Hose

Der Aristophanische Held

V. Castellani

Captive Captor Freed:

The National Theater of Ancient Rome

G. Vogt-Spira

Traditionen improvisierten Theaters bei Plautus

Einige programmatische Überlegungen

N. Yaari

Anchoring Thebes:

Defining Place and Space in Ancient Greek Theatre

A.H. Sommerstein

The Beginning and the End of Aeschylus' Danaid Trilogy

R.E. Harder

Die Figur der Helena in den Tragödien des Euripides

E. Lefèvre

Euripides' Bakchai und die politische Bedeutung seines Spätwerks

Buchbesprechungen:

M. Silk

M. Luserke (Hrsg.): Die Aristotelische Katharsis. Dokumente ihrer Deutung im 19. und 20. Jahrhundert

S. Beta

T.K. Hubbard: The Mask of Comedy. Aristophanes and the Intertextual Parabasis

Corrigendum zu DRAMA 2

Spielplan 


\section{Vorwort}

Nachdem die beiden ersten Bände von DRAMA mit antiken Dramentheorien und ihrer Rezeption (DRAMA 1) sowie Intertextualität in der griechisch-römischen Komödie (DRAMA 2) je einen Schwerpunkt aufwiesen, sollte der vorliegende dritte Band ohne ein festes Rahmenthema in einem breiten Spektrum kontrovers diskutierte Probleme des antiken Dramas beleuchten.

Der für 1995 geplante Band 4 wird wieder ein Rahmenthema aufweisen: Der Elektra-Stoff und seine Rezeption im Drama.

Heinrich-Heine-Universität Düsseldorf

Bernhard Zimmermann 